\title{
Conference Paper \\ Travelling along the Clinical Roadmap: Developing Electrospun Scaffolds for Tendon Repair
}

\author{
Lucy A. Bosworth \\ School of Materials, The University of Manchester, Oxford Road, Manchester M13 9PL, UK \\ Correspondence should be addressed to Lucy A. Bosworth; lucy.bosworth@manchester.ac.uk
}

Received 6 September 2013; Accepted 10 February 2014; Published 23 March 2014

Academic Editors: J. Gough, R. Sammons, and C. Scotchford

This Conference Paper is based on a presentation given by Lucy A. Bosworth at "UK Society for Biomaterials Annual Conference 2013" held from 24 June 2013 to 25 June 2013 in Birmingham, United Kingdom.

Copyright (C) 2014 Lucy A. Bosworth. This is an open access article distributed under the Creative Commons Attribution License, which permits unrestricted use, distribution, and reproduction in any medium, provided the original work is properly cited.

Biopolymers, such as poly( $\varepsilon$-caprolactone), can be easily electrospun to create fibrous scaffolds. It is also possible to control the alignment of the emitted fibres and further manipulate these scaffolds to create 3D yarn structures, which resemble part of the tendon tissue hierarchy. Material properties, such as tensile strength, can be tailored depending on the selection and combination of polymer and solvent used during electrospinning. The scaffolds have been proven to separately support the adhesion and proliferation of equine tendon fibroblasts and human mesenchymal stem cells whilst simultaneously directing cell orientation, which caused their alignment parallel to the underlying fibres. Implantation of scaffolds into the flexor digitorum profundus tendon of mice hindpaws yielded encouraging results with minimal inflammatory reaction and observation of cell infiltration into the scaffold. This research demonstrates the progression of electrospun fibres along the clinical roadmap towards becoming a future medical device for the treatment of tendon injuries.

\section{Introduction}

Electrospinning has become a popular technique in the field of biomaterials and tissue engineering due to the ease at which fibrous scaffolds can be fabricated. The ability to control fibre properties and create 3D structures, with architectures similar to the extracellular matrix, lends itself to a range of tissues, including bone, heart valves, trachea, and tendons [1].

As highly fibrous tissues that repeatedly transfer loads from muscle to bone, tendons are susceptible to wear and tear and spontaneous rupture. Depending on the injury sustained, surgeons can opt to repair the area of damage with autologous tendon tissue. Whilst this is classed as the "gold standard" intervention, it is not without its disadvantages: creation of a secondary site of tissue morbidity arises which can increase the risk of infection and prolong patient rehabilitation time; the ability to source suitable tissue to provide an autograft cannot be guaranteed. Consequently, alternative therapies using biomaterials are being explored.
There are a number of commercially available products that aim to repair damaged tendons including Teno Fix manufactured by Ortheon Medical, which is a permanent stainless steel anchor and suture system; Poly-Tape/AchilloCord produced by Xiros (Neoligaments), which is a dense, woven network of nondegradable synthetic polymer; and TissueMend, similar to a number of available devices, which functions as a wrap made of collagen from fetal bovine dermis to be placed around the exterior of severed tendon ends. An expert review by Chen et al. [2] discusses the pros and cons of a number of these commercially available medical devices and how they fair surgically.

With surgeons having no preferred and reliable device to use consistently, research in developing an alternative solution continues. Gels, such as collagen type I $[3,4]$ and platelet-rich plasma [5], have been investigated but their use is currently limited due to issues with purity and regulatory standards (such as the FDA and MHRA), and their inherent weak mechanical properties that are essential for this type of tissue. Electrospun fibre scaffolds are finding increasing use 


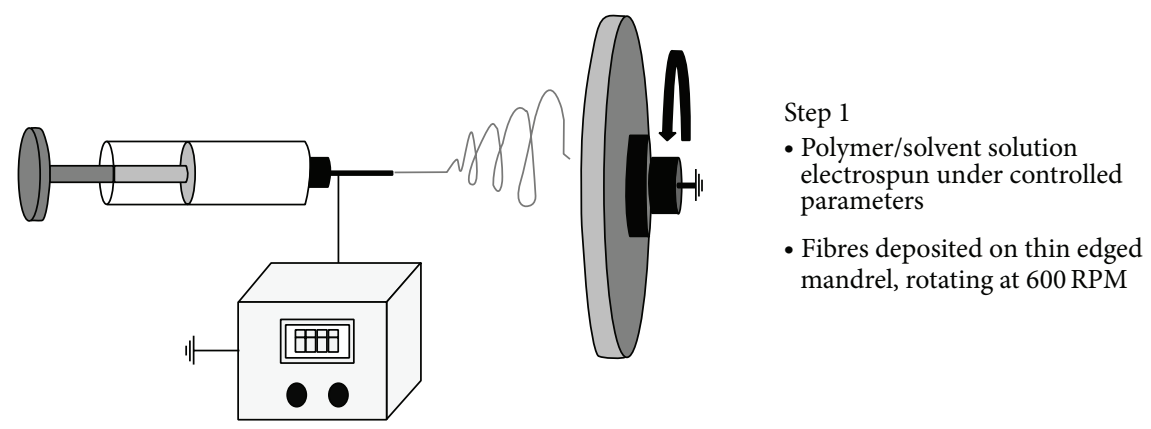

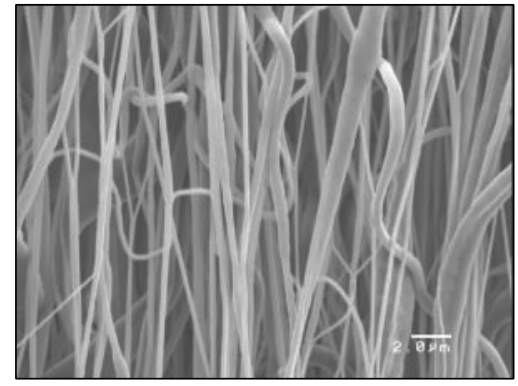

Step 2

- Deposited fibres removed from mandrel surface as 2D fibrous ribbon

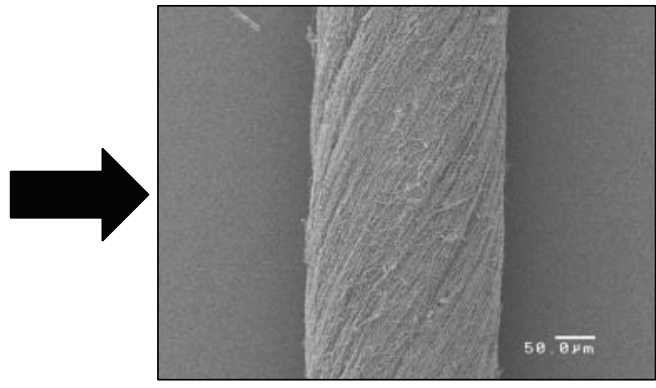

Step 3

- 2D fibrous ribbon cut to size and then twisted at either end to create 3D bundles

FIGURE 1: Schematic demonstrating the electrospinning setup and process for fabricating 2D fibrous ribbons and formation of 3D fibre bundles.

\begin{tabular}{|lccc|}
\hline Scaffold & $\begin{array}{c}\text { Fibre diameter } \\
(\mu \mathrm{m})\end{array}$ & $\begin{array}{c}\text { Young's modulus } \\
(\mathrm{MPa})\end{array}$ & $\begin{array}{c}\text { Tensile strength } \\
(\mathrm{MPa})\end{array}$ \\
\hline $\begin{array}{l}\text { PCL } \\
\text { (acetone) }\end{array}$ & & & $4.12 \pm 2.00$ \\
\hline $\begin{array}{l}\text { PCL } \\
\text { (HFIP) }\end{array}$ & $0.33 \pm 0.18$ & $12.44 \pm 4.96$ & $41.54 \pm 13.61$ \\
\hline $\begin{array}{l}\text { PCL-PLGA } \\
\text { (HFIP) }\end{array}$ & $0.44 \pm 0.11$ & $68.14 \pm 23.66$ & $5.40 \pm 0.82$ \\
\hline $\begin{array}{l}\text { PLGA } \\
\text { (HFIP) }\end{array}$ & $0.56 \pm 0.13$ & $64.45 \pm 9.70$ & \\
& $0.80 \pm 0.30$ & & \\
\end{tabular}

Figure 2: Polymer/solvent combinations for creating electrospun 3D bundles: poly( $\varepsilon$-caprolactone) PCL (acetone), PCL (1,1,1,3,3,3hexafluoroisopropanol; HFIP), 50:50 blend of PCL and PLGA (poly(lactic-co-glycolic acid)) in HFIP, and PLGA (HFIP) demonstrating scaffold morphologies from scanning electron micrographs (scale bar $20 \mu \mathrm{m}$ ), fibre diameter, and mechanical properties in terms of Young's modulus and tensile strength (mean \pm standard deviation).

as potential devices for tendon repair as it is possible to easily manipulate and control the fibre orientation to mimic the natural tissue more closely $[6,7]$.

There are several key factors, which need to be incorporated when developing synthetic scaffolds for tendon repair: the scaffold should (1) resemble the natural tendon structure, (2) be biocompatible and promote appropriate tissue healing, (3) provide sufficient mechanical strength to support new tissue formation and withstand applied forces, and (4) degrade at a rate which allows for a smooth transfer of load without premature failure or accumulation of toxic byproducts. 


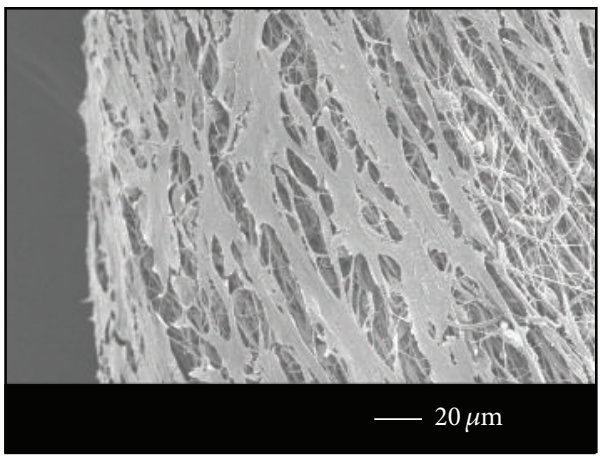

(a)

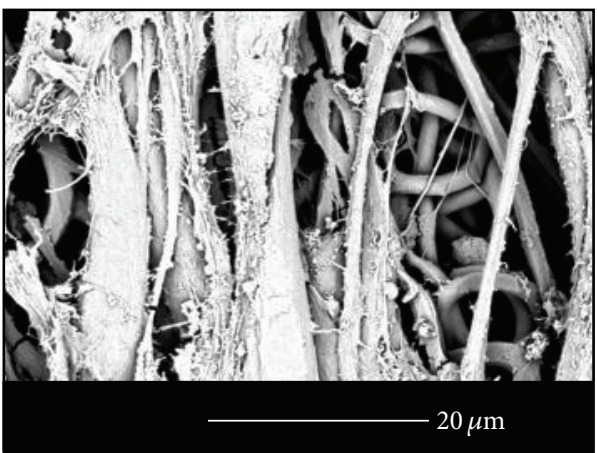

(c)

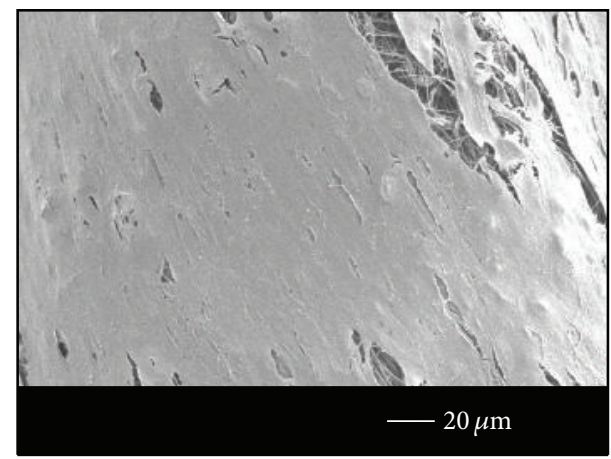

(b)

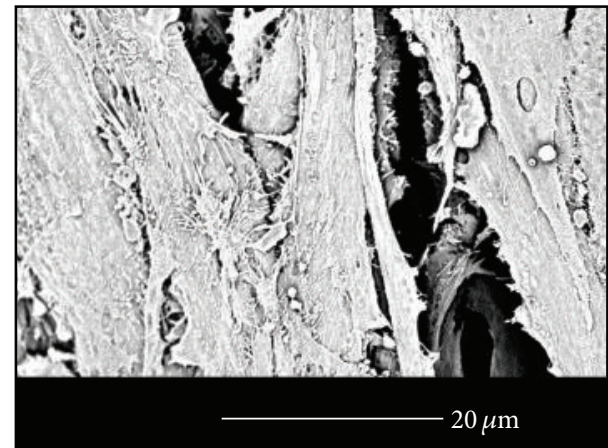

(d)

FIGURE 3: Scanning electron micrographs of poly( $\varepsilon$-caprolactone) electrospun fibres seeded with equine tendon fibroblasts after 1 week (a) and 2 weeks (b) and human mesenchymal stem cells after 1 week (c) and 2 weeks (d).
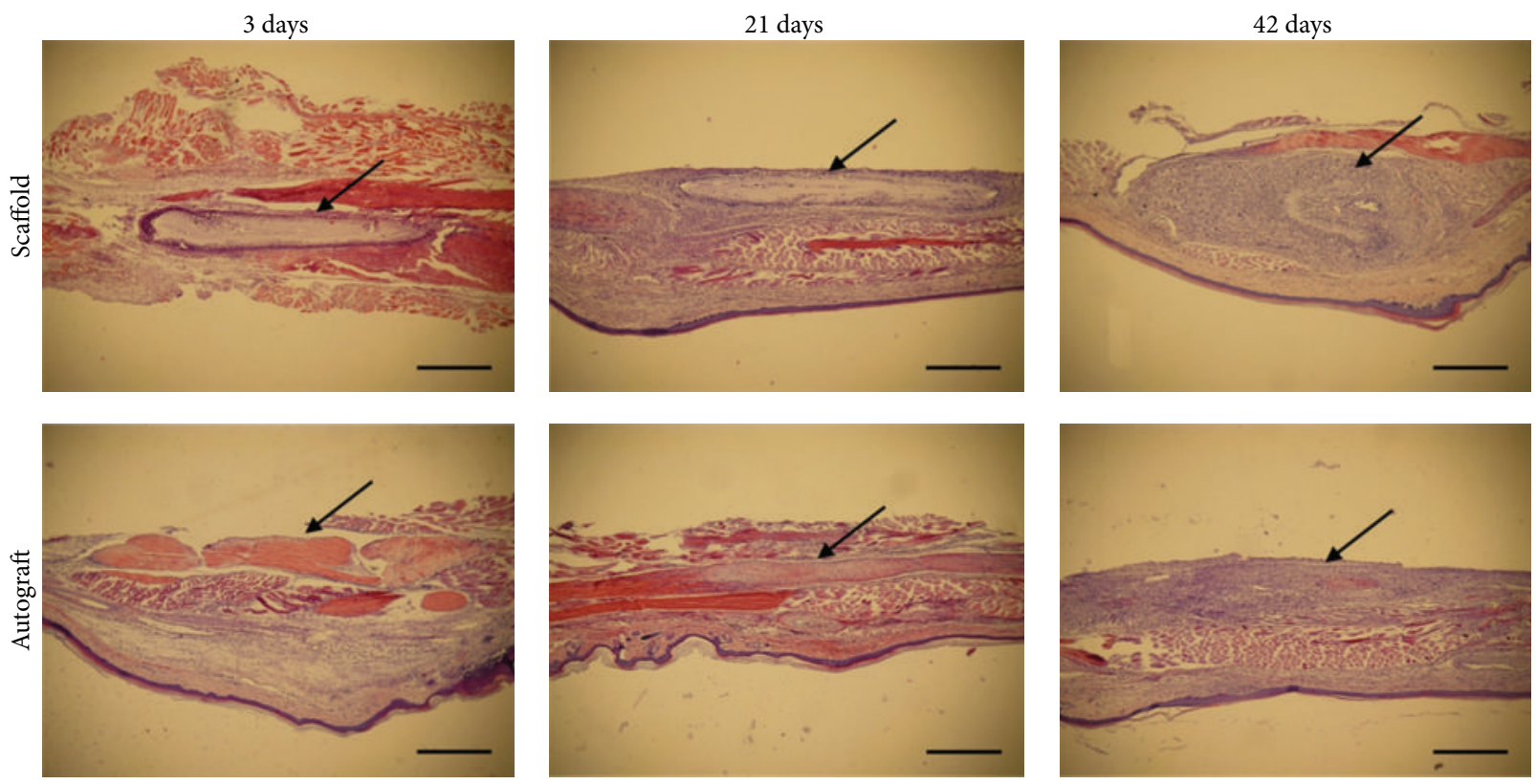

FIGURE 4: $\mathrm{H}$ and $\mathrm{E}$ light microscopy images of poly( $\varepsilon$-caprolactone) scaffolds and autograft tissue implanted into the flexor digitorum profundus tendon of mice and harvested after 3 days, 3 weeks, and 6 weeks. Arrows indicate position of graft; scale bar represents $500 \mu \mathrm{m}$. 


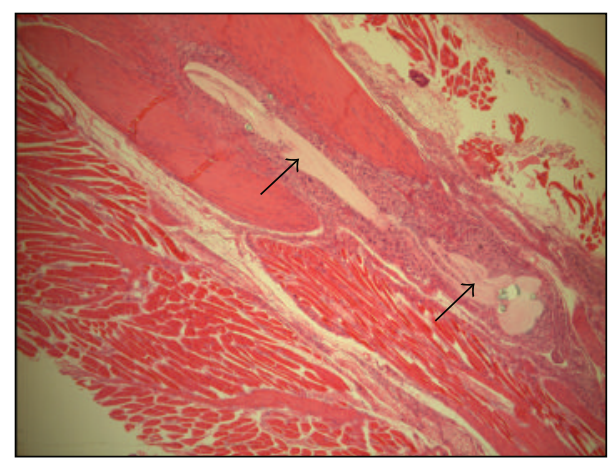

Figure 5: $\mathrm{H}$ and $\mathrm{E}$ image of medical grade poly( $\varepsilon$-caprolactone) electrospun graft implanted into flexor digitorum profundus tendon of a mouse after 6 weeks. Arrows indicate position of the graft within the surrounding tissue.

\section{Scaffold Design and Fabrication}

The last eight years have been focused on developing an electrospun fibre scaffold that aims to fulfill these criteria. Electrospun yarns are fabricated via a three-step process; firstly, a polymer-solvent solution is electrospun using predetermined parameters (voltage $-20 \mathrm{kV}$, flow rate $-1 \mathrm{~mL} / \mathrm{hr}$, and distance to collector- $20 \mathrm{~cm}$ ) onto the fine edge of a mandrel rotating at an optimised speed (600 RPM) for $15 \mathrm{~min}$. Fibres are removed from the mandrel surface as a single $2 \mathrm{D}$ flat ribbon, which is then cut to the required length and finally twisted to create a 3D yarn structure (Figure 1).

A range of synthetic and degradable polymers have been investigated, including poly( $\varepsilon$-caprolactone) (PCL), poly(lactic-co-glycolic acid) (PLGA 85:15 ), and a 50:50 blend of PCL and PLGA $85: 15$. Solvents used for dissolution of the polymers were acetone (PCL) and 1,1,1,3,3,3-hexafluoroisopropanol (HFIP) (PCL, PLGA $85: 15$, and PCL: $\left.\mathrm{PLGA}_{85: 15}\right)$. All solutions were at a concentration of $10 \% \mathrm{w} / \mathrm{v}$, which had been previously determined in a separate study [8]. Of the four polymer/solvent combinations trialled (Figure 2), PCL dissolved in HFIP resulted in smooth, bead-free fibres and fine fibre diameter $(0.44 \mu \mathrm{m})$ [9]. The tensile properties of each scaffold type were measured using an Instron 1122 with $10 \mathrm{~N}$ load cell and $5 \mathrm{~mm} / \mathrm{min}$ cross-head speed. Out of the four combinations, PCL in HFIP yielded greatest tensile strength with similarly high Young's modulus. Consequently this polymer/solvent permutation was taken forward with this research.

\section{In Vitro Assessment of Scaffolds}

As proven by a number of other researchers worldwide, PCL is able to support the adhesion and proliferation of a range of cell types [10-12]. Similarly, our electrospun scaffolds have supported the attachment of equine tendon fibroblasts and human mesenchymal stem cells (Figure 3). The morphologies of these cells, despite being different cell lines, were near identical in appearance; cells were orientated and spread parallel to the underlying fibre direction, which indicates that the scaffold structure is conferring contact guidance cues to the cells. After two weeks in culture the entire outer surface of the scaffold was covered by cells (and possible secreted extracellular matrix), which would demonstrate the scaffolds support of cell proliferation. Cells (and matrix) continued to lie adjacent to the underlying architecture over the culture period investigated.

\section{In Vivo Assessment of Scaffolds}

To assess the biological response and efficacy of the scaffolds in vivo, purpose-made defects were created in the flexor digitorum profundus tendon located within the hindpaw of mice. This was achieved by isolating the once healthy tendon and using a scalpel to create a 50\% window. PCL grafts were implanted within this window and held in place by the surrounding tissues. For comparison, the discarded tendon tissue was used as an autograft control in the opposite hindpaw of the same mouse. Mice were free to move about their cages and feed as normal. Harvest of the tissue was taken after 3 days, 3 weeks, and 6 weeks. Tissues were fixed in zinc fixative, embedded in paraffin, and sectioned with a microtome set to $7 \mu \mathrm{m}$. Sections were stained with $\mathrm{H}$ and $\mathrm{E}$ (haematoxylin and eosin) and imaged by light microscopy (Figure 4).

After 3 days, the PCL graft was clearly located within the remaining tendon tissue. Visual assessment showed that the surrounding tissue was highly cellularised, with the outer perimeter of the graft fully surrounded by cells. Following 3 weeks, cells had penetrated into the core of the scaffold, which suggested that either the porosity of the scaffold was sufficient to encourage cell infiltration or the scaffold had been subjected to an increased rate of degradation; PCL in vivo has been reported to be present in excess of one year [13], although the increased surface area exposed by the individual fibres may be a contributing factor if accelerated hydrolysis of the polymer chains has occurred. However, the migration of cells into the scaffold is vital for the long-term success of the implant; the scaffold must be biocompatible and encourage a positive tissue response; otherwise its encapsulation could lead to failure, or a void in the tissue could occur as the material degrades but no cells or tissue has penetrated through. After 6 weeks, the PCL grafts appear to have undergone significant degradation and a prominent cell response remains. However, this level of cell response was also observed in the autograft control, which would suggest that the tissue is undergoing remodelling. For this type of tissue repair, complete degradation of the scaffold at 6 weeks is too early. Tendons are slow healing tissues and time is required for the cells to secrete and organise appropriate matrix that is weight bearing. It should be noted that, for this particular study, the quality of the PCL used was chemical grade and not $100 \%$ pure. When the animal study was repeated using medical grade PCL that is regulatory approved for implantation into humans, the PCL graft remained completely intact after 6 weeks implantation and the degree of cell response and hence inflammation was reduced (Figure 5). 


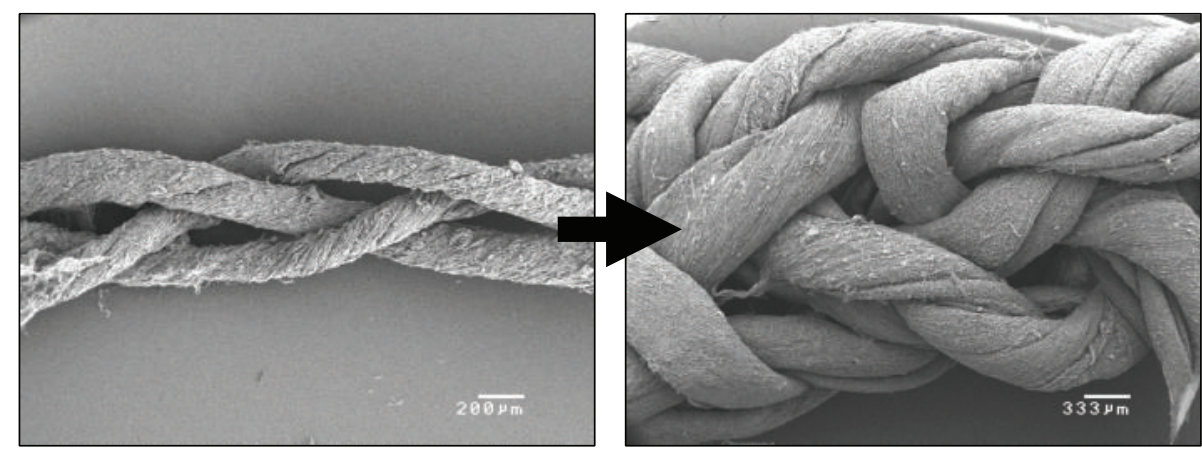

FIGURE 6: Scanning electron micrographs of several poly( $\varepsilon$-caprolactone) electrospun 3D bundles that have been manually braided to create structures of increasing size.

\section{Translation of Scaffolds from Bench to Clinic}

The end goal of the research should always be the main focus, and there are a number of hurdles that must be crossed as the research translates from lab-based investigations to clinical trials. These hurdles are imposed mainly from regulatory bodies, such as the MHRA (Medicine and Healthcare Products Regulatory Agency, UK) and FDA (Food and Drug Administration, USA), which stipulate that certain standards should be met before granting the go-ahead for clinical trials and sale of new medical devices intended for human use. Some of these hurdles involve determining what approved sterilisation technique will be routinely used for sterilising the device and ensuring that it is free from pathogens. It is important that the sterilisation technique is determined early in the project's timeline, as years of research could be wasted if the properties of the device change drastically or the material is unable to achieve sterility. A recent study conducted on our electrospun fibres proved that gamma irradiation had a significant impact on their tensile properties [14]. Irrespective of gamma dose, both Young's modulus and tensile strength were more than halved compared to the virgin scaffold. This could have detrimental consequences to the project's future, particularly as this scaffold will be used for tendon repair, a tissue that repeatedly withstands considerable tensile forces. However, by recognising this early, the problem could potentially be overcome by either increasing the starting molecular weight of the polymer to allow for the chain scission that occurs from the gamma rays or a different sterilisation technique could be trialled, such as ethylene oxide, which is currently being investigated.

Other hurdles, not related to set standards, involve the scaling of the scaffold. In this case, there are two types: scaling of the manufacturing process to make scaffolds easy to fabricate in high volume and consistent from batch to batch and scaling of the scaffold itself. All researches to date have been focused on the single, 3D electrospun scaffold. However, if this is to be translated, consideration needs to be given to the surgeon's needs. Would a surgeon be willing to spend time grafting a number of these scaffolds into a patient's damaged tendon or would they prefer a single graft that could be cut to size? Obtaining the thoughts of key opinion leaders in the field tends towards the latter. As such, the single scaffold must be developed in order to accommodate the surgeon's requirements. Possible ways to achieve this could involve braiding several single scaffolds to create interwoven structures of increasing size (Figure 6); however, this area of research currently remains under development.

\section{Conclusion}

Since the inception of this research project, the fabrication and development of electrospun fibres as 3D fibrous yarns has undergone and continues to undergo considerable testing both in vitro and in vivo to ensure that the scaffold is fully characterised, and a complete data package can be provided as and when the research translates to clinical use in patients with damaged tendons.

\section{Conflict of Interests}

The author declares that there is no conflict of interests regarding the publication of this paper.

\section{Acknowledgments}

The author thanks Dr. Sarah Cartmell and Professor Sandra Downes for guidance and supervision, and also thanks to Professor Duncan McGrouther, Dr. Jason Wong, Dr. Richard Wong, and Miss Marie O'Brien for scientific input. Thanks are also due to the EPSRC, UMIP Premier Fund, RegeNer8, and MRC-DPFS for financial support.

\section{References}

[1] L. A. Bosworth and S. Downes, Electrospinning for Tissue Regeneration, Woodhead Publishing, Cambridge, UK, 2011.

[2] J. Chen, J. Xu, A. Wang, and M. Zheng, "Scaffolds for tendon and ligament repair: review of the efficacy of commercial products," Expert Review of Medical Devices, vol. 6, no. 1, pp. 61-73, 2009.

[3] D. G. Wallace and J. Rosenblatt, "Collagen gel systems for sustained delivery and tissue engineering," Advanced Drug Delivery Reviews, vol. 55, no. 12, pp. 1631-1649, 2003. 
[4] J. Garvin, J. Qi, M. Maloney, and A. J. Banes, "Novel system for engineering bioartificial tendons and application of mechanical load," Tissue Engineering, vol. 9, no. 5, pp. 967-979, 2003.

[5] M. Cervellin, L. de Girolamo, C. Bait, M. Denti, and P. Volpi, "Autologous platelet-rich plasma gel to reduce donorsite morbidity after patellar tendon graft harvesting for anterior cruciate ligament reconstruction: a randomized, controlled clinical study," Knee Surgery, Sports Traumatology, Arthroscopy, vol. 20, no. 1, pp. 114-120, 2012.

[6] L. A. Bosworth, N. Alam, J. K. Wong, and S. Downes, "Investigation of $2 \mathrm{D}$ and $3 \mathrm{D}$ electrospun scaffolds intended for tendon repair," Journal of Materials Science: Materials in Medicine, vol. 24, no. 6, pp. 1605-11614, 2013.

[7] K. L. Moffat, A. S.-P. Kwei, J. P. Spalazzi, S. B. Doty, W. N. Levine, and H. H. Lu, "Novel nanofiber-based scaffold for rotator cuff repair and augmentation," Tissue Engineering A, vol. 15, no. 1, pp. 115-126, 2009.

[8] L. A. Bosworth and S. Downes, "Acetone, a sustainable solvent for electrospinning poly ( $\varepsilon$-caprolactone) fibres: effect of varying parameters and solution concentrations on fibre diameter," Journal of Polymers and the Environment, vol. 20, no. 3, pp. 879886, 2012.

[9] L. A. Bosworth, "Electrospinning for tendon regeneration," in Electrospinning for Tissue Regeneration, L. A. Bosworth and S. Downes, Eds., pp. 148-167, Woodhead Publishing, Cambridge, UK, 2011.

[10] D. W. Hutmacher, T. Schantz, I. Zein, K. W. Ng, S. H. Teoh, and K. C. Tan, "Mechanical properties and cell cultural response of polycaprolactone scaffolds designed and fabricated via fused deposition modeling," Journal of Biomedical Materials Research, vol. 55, no. 2, pp. 203-216, 2001.

[11] M. Sun and S. Downes, "Solvent-cast PCL films support the regeneration of NG108-15 nerve cells," in International Conference on Smart Materials and Nanotechnology in Engineering, Proceedings of SPIE, July 2007.

[12] K. Kyriakidou, G. Lucarini, A. Zizzi et al., "Dynamic co-seeding of osteoblast and endothelial cells on 3D polycaprolactone scaffolds for enhanced bone tissue engineering," Journal of Bioactive and Compatible Polymers, vol. 23, no. 3, pp. 227-243, 2008.

[13] H. Sun, L. Mei, C. Song, X. Cui, and P. Wang, "The in vivo degradation, absorption and excretion of PCL-based implant," Biomaterials, vol. 27, no. 9, pp. 1735-1740, 2006.

[14] L. A. Bosworth, A. Gibb, and S. Downes, "Gamma irradiation of electrospun poly ( $\varepsilon$-caprolactone) fibers affects material properties but not cell response," Journal of Polymer Science B: Polymer Physics, vol. 50, no. 12, pp. 870-876, 2012. 

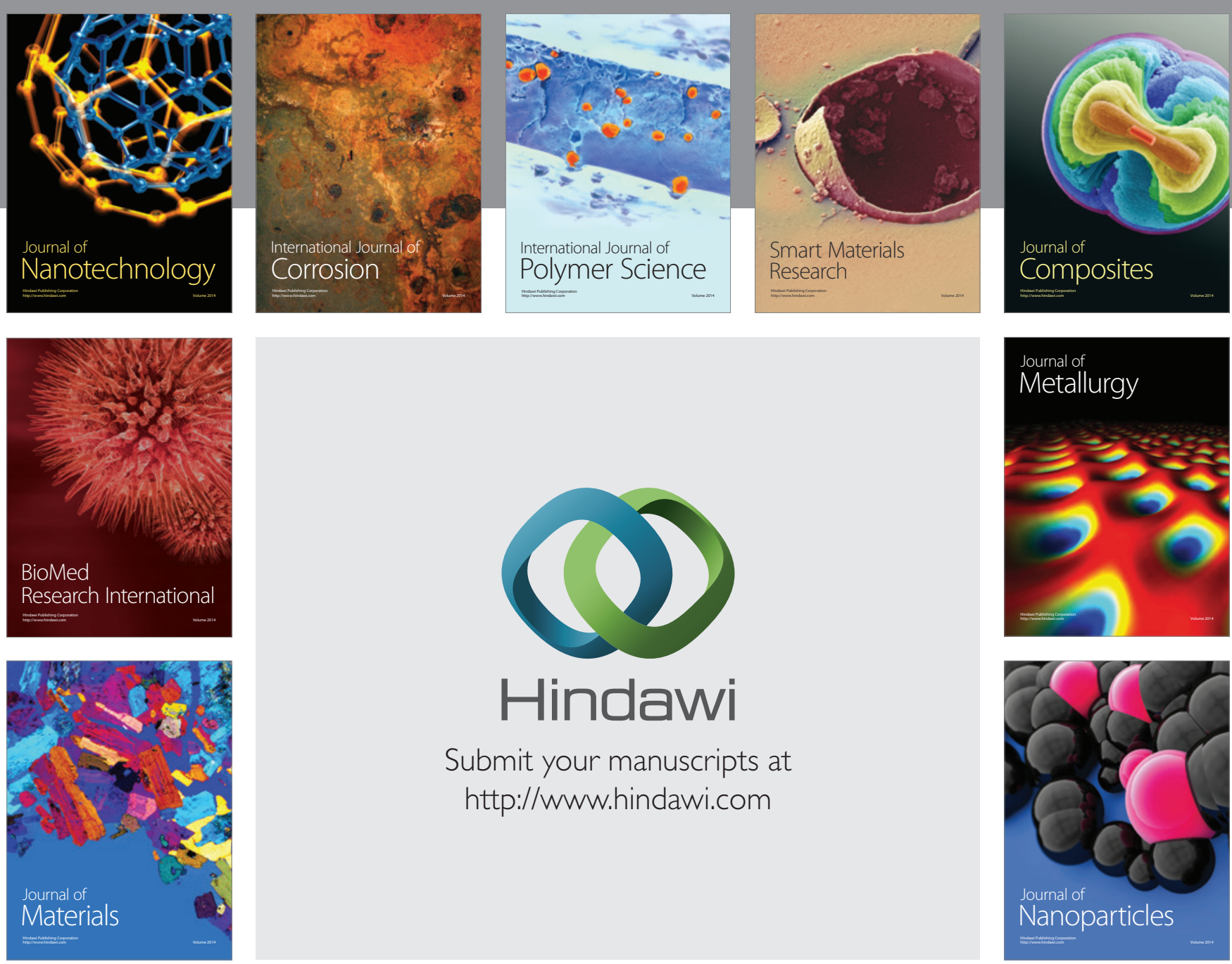

Submit your manuscripts at http://www.hindawi.com
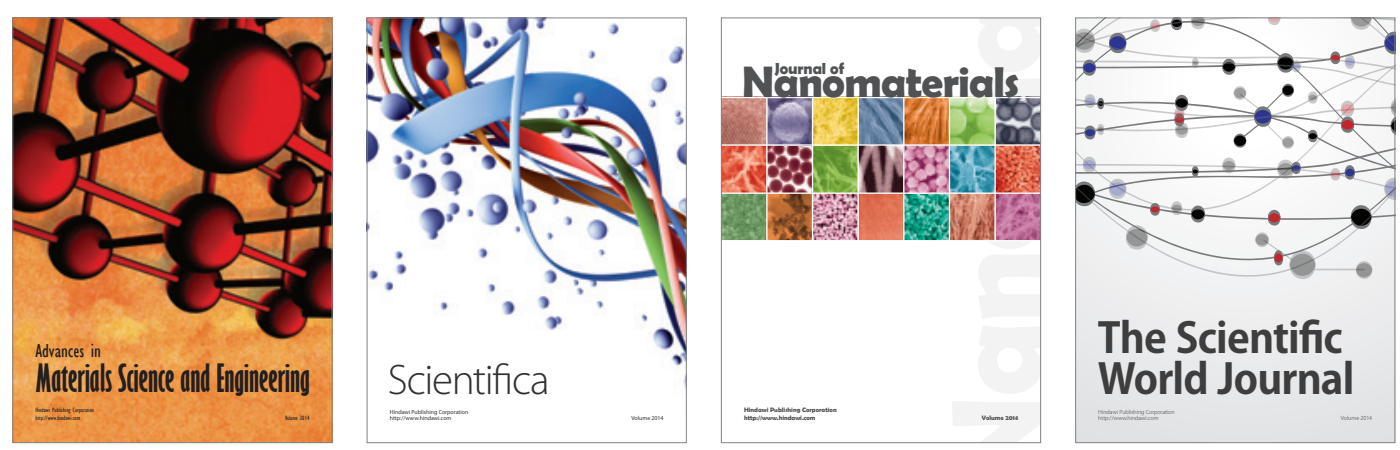

\section{The Scientific World Journal}
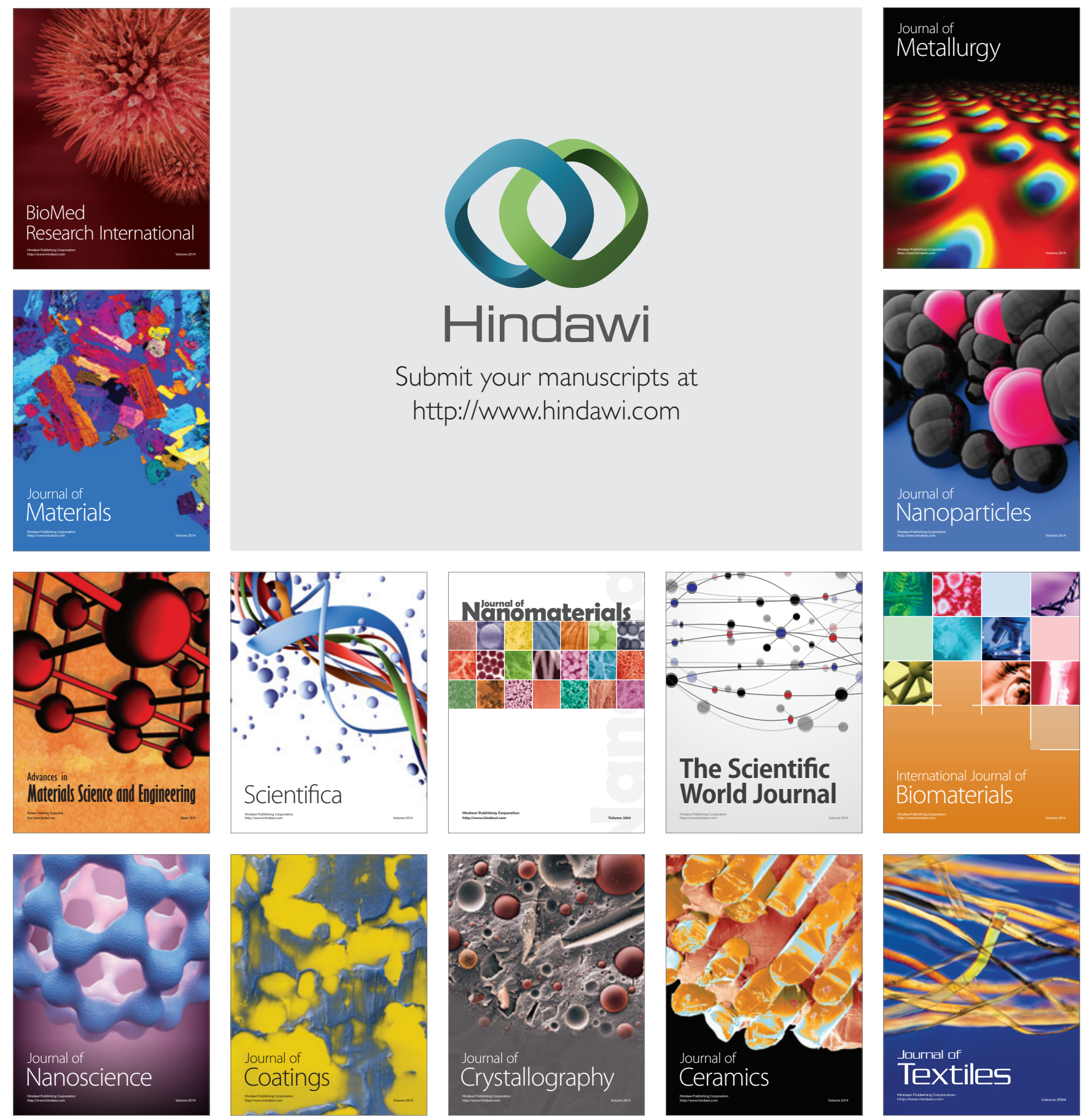